KINETIK, Vol.1, No.2, Agustus 2016, Hal. 69-78

ISSN : 2503-2259,

E-ISSN : 2503-2267

\title{
Efisien Epidemic: Pemilihan Jarak Terjauh dan Arah Pergerakan Kendaraan untuk Pendistribusian Pesan Darurat Pada Vehicular Delay Tolerant Network
}

\author{
Denar Regata Akbi ${ }^{* 1}$, Waskitho Wibisono ${ }^{2}$ \\ 1,2Teknik Informatika Institut Teknologi Sepuluh Nopember Surabaya \\ denar.regata12@mhs.if.its.ac.id ${ }^{* 1}$, waswib@if.its.ac.id ${ }^{2}$
}

\begin{abstract}
Abstrak
VANET memiliki karakteristik mobilitas kendaraan yang tinggi dan perubahan topologi yang cepat, kondisi tersebut menimbulkan proses komunikasi data yang sering terputus-putus. Teknologi Vehicular Delay Tolerant Network (VDTN) dapat meminimalisir kondisi tersebut. Protokol Epidemic merupakan salah satu protokol yang digunakan untuk pendistribusian pesan pada jaringan vanet. Tetapi mekanisme pada protokol Epidemic menyebabkan jumlah pesan yang relatif banyak, sehingga berdampak pada proses pendistribusian pesan yang tidak efisien dan menurunkan kinerja dari jaringan. Masalah tersebut dapat diselesaikan menggunakan mekanisme pedistribusian pesan menggunakan protokol usulan dari peneliti, yaitu protokol eEpidemic. Protokol e-Epidemic merupakan pengembangan dari protokol Epidemic dengan memperhatikan arah pergerakan kendaraan dan juga pemilihan kendaraan dengan jarak terjauh. Hasil penelitian berdasarkan jumlah pendistribusian pesan menunjukkan pada protokol e-Epidemic rata-rata jumlah pendistribusian pesan sebanyak $8 \%$ dan jumlah pesan penggunaan protokol Epidemic sebesar 92\%. Dan berdasarkan nilai Delay, Protokol e-Epidemic hanya memiliki Delay sebesar 17\% sedangkan Protokol Epidemic sebesar 83\%.
\end{abstract}

Kata kunci: Vehicular Delay Tolerant Network, Protokol Epidemic, Protokol e-Epidemic, Pendistribusian pesan

\begin{abstract}
The characteristics of VANET are in its high mobility vehicle and the rapid change of its topology, which could possibly hamper the data communication process. Technology of Vehicular Delay Tolerant Network (VDTN) could minimize this issue. Epidemic protocol is the protocol in charge to distribute the messages in VANET. However, the mechanism of Epidemic protocol tends to process the messages in large amount at once, which causes inefficient distribution and decreases the network performance. The researcher purposes to solve this issue by using message distribution mechanism, namely e-Epidemic protocol. E-Epidemic protocol is the developing of Epidemic protocol by observing the vehicles' direction movement and also cognizing the farthest vehicles. The findings show that the average of message distributions for e-Epidemic protocol and Epidemic protocol are $8 \%$ and $92 \%$ respectively. Meanwhile, in term of Delay, e-Epidemic protocol and Epidemic protocol have 17\% and $83 \%$ delay respectively.
\end{abstract}

Keywords: Vehicular Delay Tolerant Network, Epidemic protocol, e-Epidemic protocol, Message distribution

\section{Pendahuluan}

\subsection{Latar Belakang}

Vehicular Ad hoc Network (VANET), merupakan sebuah teknologi baru yang potensial dalam hal menangani komunikasi data antar kendaraan yang bergerak, untuk melakukan komunikasi data antar kendaraan, VANET menggunakan pendekatan yang mengintegrasikan jaringan ad hoc, wireless LAN (WLAN), dan teknologi seluler [1]. VANET memiliki karakteristik mobilitas kendaraan yang tinggi dan perubahan topologi yang cepat [2]. Kondisi mobilitas yang tinggi dan perubahan topologi yang cepat pada jaringan VANET, berpotensi menimbulkan masalah ketika proses komunikasi data terjalin antar dua atau lebih kendaraan, yaitu terjadinya koneksi yang sering terputus-putus [3]. Masalah komunikasi data yang dihadapi VANET, perlu diminimalisir agar komunikasi data antar kendaraan dapat terjalin meskipun dengan kondisi koneksi sering terputus-putus. Kondisi tersebut dapat diminimalisir dengan menerapkan metode 
Store Carry and Forward dari teknologi Delay Tolerant Network (DTN) [3], serta menggunakan metode tersebut jika koneksi antar kendaraan terputus atau belum adanya koneksi yang terjalin antar kendaraan, maka pesan disimpan sementara pada setiap kendaraan sampai terjalin koneksi dengan kendaraan lain [4]. Kombinasi teknologi VANET dan DTN dikenal dengan istilah Vehicular Delay Tolerant Network (VDTN) [3].

Protokol Epidemic dikembangkan berdasarkan kebutuhan untuk pendistribusian pesan secara efisien dalam jaringan. Ragam penelitian dalam hal pendistribusian pesan yang dikembangkan pada penelitian sebelumnya, menggunakan protokol Epidemic sebagai protokol dasar. Epidemic algorithms for reliable and efficient information dissemination in vehicular [5], Prioritized Epidemic routing for opportunistic networks [6] merupakan contoh pengembangan dalam hal pendistribusian pesan menggunakan protokol Epidemic. Kelemahan penggunaan protokol Epidemic dalam hal pendistribusian pesan adalah jika setiap node diizinkan untuk melakukan penularan pesan pada setiap node tetangganya, maka terdapat banyak pesan dalam jaringan, sehingga dapat menurunkan kinerja dari jaringan.

Pada kasus kendaraan darurat seperti ambulans, pendistribusian pesan darurat ke kendaraan lain efektif jika metode broadcast pada protokol Epidemic diterapkan dengan menggunakan mekanisme Multi Hop, tetapi hal tersebut menimbulkan beberapa masalah, (i) jika setiap kendaraan yang telah menerima pesan darurat dapat melakukan broadcast pesan ke kendaraan lain, hal tersebut menurunkan kinerja dari jaringan, (ii) jika dalam jaringan terdapat kondisi dimana jarak antar kendaraan terlampau jauh, harus terdapat mekansime penanganan pesan, apakah pesan harus disimpan terlebih dahulu sampai terdapat kendaraan lain yang bisa didistribusikan suatu pesan, atau pesan harus dibuang, (iii) jika pesan tanggap darurat terus didistribusikan oleh kendaraan lain pada jaringan, sedangkan posisi kendaraan darurat saat ini berada jauh dari posisi sebelumnya karena pergerakan, maka pesan yang didistribusikan oleh kendaraan lain tersebut dapat membebani jaringan karena sebenarnya pesan tersebut sudah tidak dibutuhkan lagi karena kendaraan darurat sudah berada di posisi lain. Dari beberapa masalah tersebut, strategi pendistribusian pesan yang efisien, handal, dan ketepatan pemilihan hop berikutnya serta penanganan pesan terhadap kondisi topologi VANET yang dinamis dan cepat berubah, merupakan suatu tantangan bagi peneliti untuk melakukan penelitian pada kasus pendistribusian pesan yang terjadi pada jaringan VANET.

Penelitian ini, peneliti mengusulkan perbaikan performa mekanisme pendistribusian pesan pada protokol Epidemic di lingkungan VANET, dengan melakukan pemilihan kandidat node yang bertugas untuk melakukan re-broadcast dan carrier pesan untuk meminimalisir jumlah pesan yang didistribusikan pada proses pendistribusian pesan, selain itu peneliti mengkombinasikan metode Store Carry and Forward untuk mengatasi kondisi topologi pada jaringan VANET yang dinamis.

\subsection{Landasan Teori}

\subsubsection{Vehicular Ad hoc Network}

Vehicular Ad hoc Network (VANET) merupakan sub-klas dari mobile ad hoc network (MANET) yang mempunyai karakteristik mobilitas tinggi dan koneksi yang bersifat intermittent [7]. VANET merupakan teknologi yang muncul untuk mengintegrasikan kemampuan jaringan nirkabel pada kendaraan. Ide dari jaringan VANET (i) Terdapat konektivitas antar kendaraan pada jalan raya (ii) Komunikasi yang efisien antar kendaraan pada jalan raya memungkinkan terbentuknya Intelligent Transportation Systems (ITS). Oleh karena itu, VANET disebut juga Intervehicle Communications (IVC) atau Vehicle-to-Vehicle (V2V) communicationsi [8]. Perbedaan mendasar antara VANET dengan MANET adalah (i) setiap node bergerak dengan kecepatan yang sangat tinggi, (ii) perubahan topologi sangat dinamis, (iii) memiliki media penyimpanan dan sumber daya yang mencukupi, (iv) komunikasi sulit terjalin karena setiap node bergerak dengan cepat dan perubahan topologi sangat dinamis [9].

\subsubsection{Delay Tolerant Network}

Delay Tolerant Network (DTN) merupakan arsitektur jaringan yang dirancang untuk kondisi jaringan yang mempunyai karakteristik (a) konektivitas sering terputus-putus, (b) mempunyai waktu delay yang cukup lama, (c) kecepatan data bersifat asimetris, dan (d) mempunyai tingkat kesalahan pengiriman yang tinggi [10].

Mekanisme transmisi paket data pada DTN tidak memerlukan koneksi secara langsung antara node sumber dan node tujuan, tetapi transmisi paket data antara node sumber dan node tujuan dilakukan hop-by-hop dengan memanfaatkan node perantara yang terhubung dengan node sumber seperti terlihat pada Gambar 1 [11]. 
Gambar 1 (a) node A sebagai node sumber mengirimkan paket data ke node B sebagai node perantara, kemudian node $\mathrm{B}$ mengirimkan paket data ke node $\mathrm{D}$ sebagai node perantara selanjutnya, paket data yang diterima oleh node $\mathrm{D}$ disimpan terlebih dahulu karena tidak ada node perantara selanjutnya yang terbuhung dengan node D. Gambar 1 (b) node D menyimpan dan membawa paket data sampai bertemu dengan node perantara selanjutnya, node $\mathrm{D}$ mengirimkan paket data ke node $\mathrm{E}$, kemudian node $\mathrm{E}$ mengirimkan paket data ke node $\mathrm{F}$ sebagai node tujuan.

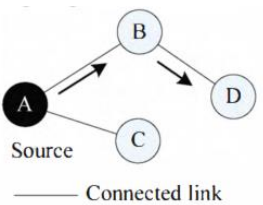

a. Paket data ditransfer ke node $D$, dan disimpan oleh node $D$

Gambar 1. Gambaran Singkat Transmisi Jaringan DTN [11]

\subsubsection{Metode Store Carry and Forward}

Metode Store Carry and Forward, digunakan untuk menyelesaikan masalah pertukaran paket data pada jaringan DTN, mekanisme pertukaran paket data Store Carry and Forward mengadopsi pertukaran paket data pada sistem pos [11].

Masalah pertukaran paket data pada jaringan DTN yang menggunakan metode Store Carry and Forward terkait dengan tidak tersedianya jalur pengiriman end-to-end, konektivitas yang terputus-putus, dan Delay yang tinggi. Dengan menggunakan paradigma pertukaran pesan store-and-forward dengan memanfaatkan pergerakan node sebagai sarana untuk menyampaikan pesan, memungkinkan keseluruhan pesan pada jaringan DTN dapat diteruskan dari sebuah media penyimpanan pada sebuah node ke media penyimpanan pada node lainnya sampai node tersebut berkomunikasi dengan node lainnya dan kembali diteruskan ke node lainnya begitu seterusnya hingga mencapai node tujuan. Gambar 2 merupakan ilustrasi dari metode Store Carry and Forward pada DTN.

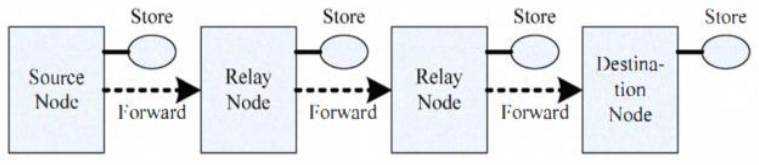

Gambar 2. Store Carry and Forward pada DTN [11]

\subsubsection{Protokol Delay Tolerant Network}

DTN mempunyai enam jenis protokol routing (i) Direct Delivery (DD), (ii) First Contact (FC), (iii) Spray and Wait (iv), PRoPHET (v), Max-Prop, dan (vi) Epidemic. Mekanisme pengiriman paket data setiap protokol DTN mempunyai karakteristik yang berbeda, terdapat tiga jenis kategori pengiriman paket data berdasarkan jumlah paket data yang dikirimkan (i) single-copy, (ii) $n$-copy, dan (iii) unlimited-copy [12].

Kategori single-copy, hanya terdapat satu salinan dari setiap paket data dalam jaringan, protokol yang termasuk dalam kategori single-copy adalah direct delivery dan first contact. Kategori $n$-copy, terdapat beberapa salinan dari setiap paket data dalam jaringan, protokol yang termasuk dalam kategori $n$-copy adalah spray and wait, sedangkan kategori unlimited-copy, terdapat banyak salinan dari setiap paket data dalam jaringan, protokol yang termasuk dalam kategori unlimited-copy adalah PRoPHET, Max-Prop, dan Epidemic [12].

\subsubsection{Protokol Epidemic}

Protokol Epidemic merupakan salah satu protokol DTN yang termasuk dalam kategori protokol unlimited-copy, dengan menggunakan mekanisme broadcast untuk melakukan pengiriman paket data [12].

\subsubsection{Mekanisme Kerja Protokol Epidemic}

Mekanisme kerja dari protokol Epidemic adalah jika terdapat node yang memiliki paket data dan terdapat beberapa node tetangga yang berada pada jangkauannya, maka node 
tersebut menulari setiap node tetangga dengan paket data dan setiap node tetangga juga diizinkan untuk menulari node tetangganya yang berada pada jangkauannya, seperti terlihat pada Gambar 3.

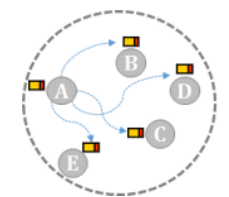

(a) Node A melakukan broadcast paket data

kepada node tetangga yang berada pada jangkauannya

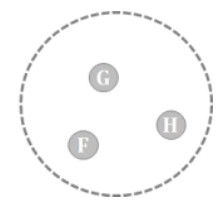

(b) Node A melakukan broadcast paket data kepada node tetangga yang berada pada jangkauannya

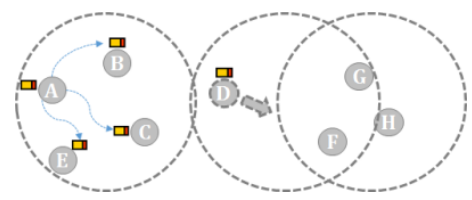

(c) Node A melakukan broadcast paket data kepada node tetangga yang berada pada jangkauannya

Gambar 3. Ilustrasi Mekanisme Pengiriman Paket Data Protokol Epidemic

\subsubsection{Euclidean Distance}

Euclidean Distance merupakan salah satu metode yang digunakan untuk menghitung jarak garis lurus antara titik $X(X 1, X 2, \ldots . X n)$ dan titik $Y(Y 1, Y 2, \ldots Y n)$. Metode Euclidean Distance memiliki rumus pengembangan sesuai dengan keadaan ruang. Persamaan dibawah ini merupakan rumus Euclidean Distance yang digunakan untuk menghitung jarak dalam ruang dua dimensi. Perhitungan jarak menggunakan pada Euclidean Distance diberikan pada Persamaan 1.

$$
d_{(x, y)}=\sqrt{\left(x_{1}-x_{2}\right)^{2}+\left(y_{1}-y_{2}\right)^{2}}
$$

Pada penelitian ini, perhitungan menggunakan Euclidean Distance digunakan untuk menghitung jarak terjauh kendaraan yang berada didepan kendaraan pengirim, dimana kendaraan yang memiliki jarak terjauh dari pengirim dianggap dan dipilih sebagai kendaraan yang bertugas untuk melakukan re-broadcast dan carrier pesan.

\subsubsection{Menghitung Arah Pergerakan Kendaraan}

Perhitungan arah pergerakan kendaraan berfungsi untuk mengetahui suatu kendaraan bergerak searah atau sebaliknya dengan kendaraan pengirim. Perhitungan arah pergerakan kendaraan diberikan pada Persamaan 2.

$$
\theta=\tan ^{-1} \frac{y_{2}-y_{1}}{x_{2}-x_{1}}
$$

Pada penelitian ini, perhitungan arah kendaraan digunakan untuk melakukan pemilihan kendaraan yang searah dengan kendaraan pengirim, dimana kendaraan yang mempunyai pergerakan searah dengan kendaraan pengirim, merupakan kendaraan yang dipilih untuk dikirimi pesan oleh kendaraan pengirim.

\subsubsection{Simulator The One Opportunistic Network Environment (ONE)}

The Opportunistic Network Environment (ONE), merupakan simulator berbasis java yang fokus menawarkan simulasi DTN yang handal dan dapat dengan fleksibel dikembangkan dikemudian hari. The ONE dikembangkan secara modular sehingga memungkinkan untuk turut berpartisipasi dengan mengembangkan modul-modul yang terdapat di dalam simulator [12].

The ONE mensimulasikan agent DTN, yang disini disebut sebagai node, mempunyai kemampuan bertindak sebagai sebuah router dengan paradigma Store Carry and Forward. Setiap node mempunyai kapabilitas berupa kemampuan pergerakan, routing pesan, kapasitas penyimpanan, dan interface wireless network [12].

\section{Metode Penelitian}

Penelitian yang dilakukan dibagi menjadi 2 tahap utama pembangunan sistem, yaitu tahap pengembangan modifikasi protokol Epidemic dan pembangunan model pergerakan KINETIK Vol.1, No.2, Agustus 2016, Hal. 69-78 
seperti terlihat pada Gambar 4. Dari beberapa tahapan tersebut, pembangunan sistem diimplementasikan dan disimulasikan menggunakan The Oportunistic Network Environment (ONE) simulator.

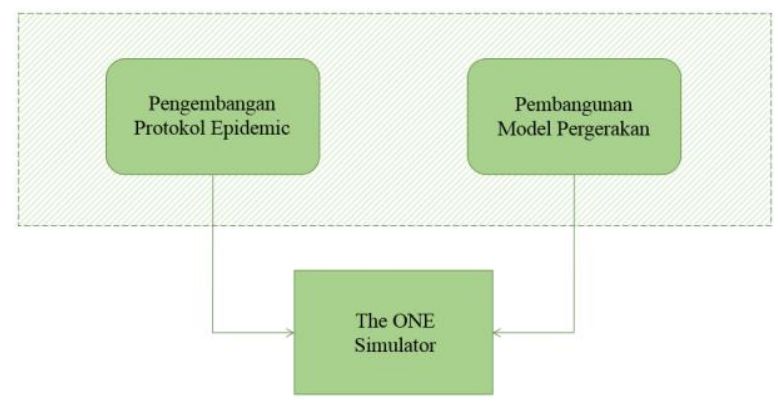

Gambar 4. Tahapan Pembangunan Sistem

Pada bagian tahap pengembangan protokol Epidemic, dapat dibagi lagi menjadi dua tahapan, (i) menganalisis kinerja dari protokol Epidemic, karena pengembangan protokol yang diusulkan memanfaatkan dan memodifikasi mekanisme kerja dari protokol Epidemic, (ii) dilakukan tahapan pengembangan protokol Epidemic yang berpedoman pada analisis yang telah dilakukan terhadap protokol tersebut, pada tahapan pengembangan ini dapat dibagi menjadi beberapa sub tahapan (ii.i) penambahan mekanisme pemilihan jarak node terjauh untuk melakukan re-broadcast dan carrier pesan (ii.ii) penambahan mekanisme expired time untuk membatasi berapa lama pesan dapat berada dan beredar dalam jaringan (ii.iii) penambahan mekanisme spatial threshold untuk membatasi pendistribusian pesan yang sudah tidak dibutuhkan lagi dalam jaringan dan yang terakhir (ii.iv) penambahan arah pergerakan kendaraan untuk membatasi pengiriman yang hanya dilakukan pada kendaraan yang berjalan searah dengan kendaraan pengirim.

Pada tahap pembangunan model pergerakan, dapat dibagi menjadi dua tahapan, (i) tahap pembuatan peta, pada tahap pembuatan peta dilakukan pembuatan sebuah peta sesuai dengan daerah perkotaan dimana terdapat belokan berupa pertigaan maupun perempatan, nantinya peta tersebut digunakan untuk media simulasi skenario-skenario yang direncanakan untuk menguji sistem yang lama maupun sistem yang baru dan, (ii) tahap pembuatan jalur pergerakan kendaraan dilakukan untuk membuat pergerakan setiap kendaraan pada peta, pada tahap ini dilakukan penarikan garis antara simpul satu dengan simpul yang lain sehingga terbentuk jalur pergerakan setiap kendaraan pada peta.

\subsection{Parameter Pengujian Sistem}

Parameter simulasi digunakan sebagai parameter utama dalam konfigurasi untuk menjalankan simulasi dan pengujian sistem seperti terlihat pada Tabel 1.

Tabel 1. Parameter Pengujian Simulator

\begin{tabular}{cll}
\hline No & \multicolumn{1}{c}{ Keterangan } & \multicolumn{1}{c}{ Detail } \\
\hline 1 & Simulator & The ONE \\
\hline 2 & Waktu simulasi & Unlimit milisecond \\
\hline 3 & Area simulasi & $2000 \mathrm{~m} \times 2000 \mathrm{~m}$ \\
\hline 4 & Radius transmisi & 110 meter \\
\hline 5 & Model koneksi & Intermittent Network \\
\hline 6 & Banyaknya kendaraan & $10,20,30,40,50$ \\
\hline 7 & Kecepatan kendaraan & $10 \mathrm{~km} / \mathrm{jam}-80 \mathrm{~km} / \mathrm{jam}$ \\
\hline 8 & Model pergerakan & jalan perkotaan $($ urban $)$ \\
\hline 9 & Protokol & Epidemic, e-Epidemic \\
\hline
\end{tabular}

\subsection{Skenario Pengujian Sistem}

Skenario pengujian sistem dirancang untuk menguji kinerja dari sistem yang baru dan dibandingkan dengan sistem yang lama, skenario-skenario yang disusun dapat terlihat pada Tabel 2. 


\subsection{Evaluasi dan Analisis Hasil Pengujian Sistem}

Pada bagian ini dilakukan evaluasi dan analisis hasil dari pengujian. Evaluasi dari sistem dilakukan dengan melakukan pengolahan data berupa pesan dalam jaringan. Hasil dari pengolahan data pada protokol e-Epidemic, dibandingkan dengan hasil dari pengolahan data pada protokol Epidemic untuk melihat sejauh mana peningkatan kinerja dari protokol yang diusulkan dengan menjalankan beberapa skenario pengujian yang telah dirancang dan parameter-parameter sesuai dengan ketentuan. Perbandingan hasil pengolahan data antara protokol e-Epidemic dan Epidemic dilakukan menggunakan Persamaan 3 dan Persamaan 4.

Tabel 2. Skenario Pengujian Sistem

\begin{tabular}{llll}
\hline No & \multicolumn{1}{c}{ Skenario } & \multicolumn{1}{c}{ Keterangan } \\
\hline 1 & $\begin{array}{l}\text { Pemilihan kendaraan terjauh sebagai } \\
\text { kendaraan penerima dan kendaraan } \\
\text { pengirim. }\end{array}$ & $\begin{array}{l}\text { Penerapan pada kendaraan bergerak secara } \\
\text { random dan dilakukan berulang kali dengan } \\
\text { nilai indikator yang sama. } \\
\text { Arah pergerakan kendaraan pengirim dan } \\
\text { kendaraan penerima. }\end{array}$ & $\begin{array}{l}\text { Penerapan pada kendaraan bergerak secara } \\
\text { random, digunakan untuk menentukan } \\
\text { proses pengiriman pesan. }\end{array}$ \\
3 & $\begin{array}{l}\text { Banyaknya pesan yang dihasilkan pada } \\
\text { Protokol Epidemic dan Protokol e- } \\
\text { Epidemic }\end{array}$ & $\begin{array}{l}\text { Penerapan pada kendaraan bergerak sesuai } \\
\text { ketentuan, dengan nilai-nilai indikator yang } \\
\text { Nilai Delay yang dibutuhkan dalam proses } \\
\text { pengiriman pesan pada Protokol Epidemic } \\
\text { dan Protokol e-Epidemic. }\end{array}$ & $\begin{array}{l}\text { Penerapan pada kendaraan bergerak sesuai } \\
\text { ketentuan, dengan nilai-nilai indikator yang } \\
\text { sama pada kedua protokol. }\end{array}$ \\
\hline
\end{tabular}

$$
\begin{aligned}
& P_{\text {epidemic }}=\frac{\text { epidemic }}{(\text { epidemic }+e-\text { pidemic })} \times 100 \% \\
& P_{\text {e-epidemic }}=\frac{e-\text { epidemic }}{(e-\text { pidemic }+ \text { epidemic })} \times 100 \%
\end{aligned}
$$

\section{Hasil Penelitian dan Pembahasan}

Pada penelitian ini, berfokus pada proses pendistribusian pesan yang berhubungan dengan jumlah pesan pada jaringan, pemilihan kendaraan dengan jarak terjauh dari kendaraan pengirim, arah pergerakan kendaraan, serta nilai Delay yang dihasilkan pada proses pendistribusian pesan antara kendaraan pengirim dengan kendaraan penerima, baik pada Protokol e-Epidemic dan Protokol Epidemic.

\begin{tabular}{|c|c|c|c|}
\hline Percobaan & \multirow[t]{17}{*}{ Range Waktu (ms) } & Jumlah Pesan Epidemic & Jumlah Pesan e-Epidemic \\
\hline 1 & & 3285 & 159 \\
\hline 2 & & 1273 & 337 \\
\hline 3 & & 608 & 93 \\
\hline 4 & & 1135 & 228 \\
\hline 5 & & 1442 & 69 \\
\hline 6 & & 3708 & 222 \\
\hline 7 & & 4331 & 278 \\
\hline 8 & & 2300 & 192 \\
\hline 9 & & 1634 & 154 \\
\hline 10 & & 2510 & 110 \\
\hline 11 & & 3367 & 217 \\
\hline 12 & & 2254 & 115 \\
\hline 13 & & 2430 & 244 \\
\hline 14 & & 1941 & 174 \\
\hline 15 & & 1397 & 95 \\
\hline Rata-Rata & & 2241 & 180 \\
\hline
\end{tabular}

Tabel 3. Jumlah Pesan dalam Jaringan pada Protokol Epidemic dan e-Epidemic 


\subsection{Pengujian Sistem terhadap Jumlah Pesan}

Pada 15 percobaan yang dilakukan dalam rentang waktu $7000 \mathrm{~ms}$, rata-rata pesan terdapat pada protokol Epidemic sebanyak 2241 pesan, sedangkan protokol e-Epidemic menghasilkan rata-rata sebanyak 180 pesan, sehingga dengan menggunakan Persamaan 3 dan Persamaan 4 menunjukkan bahwa pesan yang dimiliki oleh Protokol Epidemic sebesar $92 \%$, sedangkan pada protokol e-Epidemic sebesar $8 \%$. Data hasil uji terlihat pada Tabel 3 dan tertuang pada Gambar 5.

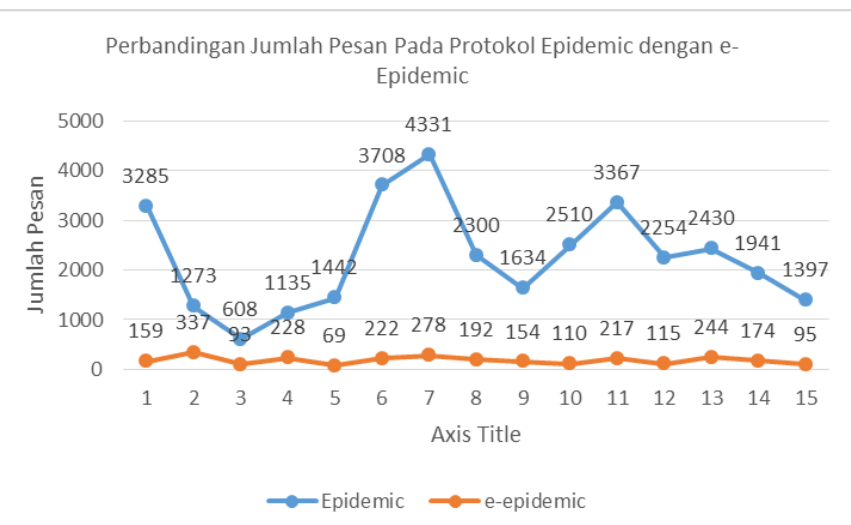

Gambar 5. Grafik Jumlah Pesan dalam Jaringan pada Protokol Epidemic dan e-Epidemic

Tabel 4. Keterangan Kejadian Pemilihan Kendaraan dengan Jarak Terjauh

\begin{tabular}{|c|c|c|c|c|c|}
\hline $\begin{array}{c}\text { Percobaan } \\
\text { ke- }\end{array}$ & $\begin{array}{l}\text { Kendaraan } \\
\text { Pengirim }\end{array}$ & $\begin{array}{c}\text { Jumlah } \\
\text { Kendaraan }\end{array}$ & ID Kendaraan & Jarak & $\begin{array}{c}\text { Kendaraan } \\
\text { Terpilih }\end{array}$ \\
\hline 1 & Ambulance1 & 2 & Mobil_B1, Mobil_C1 & 8,33 & Mobil_C1 \\
\hline 2 & Mobil_C1 & 2 & Mobil_D1, Mobil_C2 & 42,78 & Mobil_C2 \\
\hline 3 & Mobil_A1 & 2 & Mobil_D1, Mobil_C1 & 53,77 & Mobil_C1 \\
\hline 4 & Mobil_B2 & 2 & Mobil_B2, Mobil_C1 & 83,103 & Mobil_C1 \\
\hline 5 & Ambulance1 & 2 & Mobil_C1, Mobil_B1 & 92,23 & Mobil_C1 \\
\hline 6 & - & - & - & - & - \\
\hline 7 & Ambulance1 & 2 & Mobil_C1, Mobil_C2 & 67,108 & mobil_C2 \\
\hline \multirow[t]{13}{*}{8} & Ambulance2 & 3 & $\begin{array}{c}\text { Mobil_A2, mobil_C1, } \\
\text { Mobil_B1 }\end{array}$ & $\begin{array}{c}22,22 \\
27 \\
\end{array}$ & Mobil_B1 \\
\hline & Mobil_A2 & 2 & Mobil_C1, Mobil_B1 & 3,7 & Mobil_B1 \\
\hline & Mobil_A1 & 2 & Mobil_A2, mobil_C1 & 108,108 & Mobil_A2 \\
\hline & Ambulance1 & 2 & Mobil_A2, mobil_C1 & 108,108 & Mobil_A2 \\
\hline & Ambulance1 & 2 & Mobil_A2, mobil_C1 & 107,107 & Mobil_A2 \\
\hline & Ambulance1 & 2 & Mobil_A2, mobil_C1 & 108,108 & Mobil_A2 \\
\hline & Ambulance1 & 2 & Mobil_A2, mobil_C1 & 102,102 & Mobil_A2 \\
\hline & Ambulance1 & 2 & Mobil_A2, mobil_C1 & 102,102 & Mobil_A2 \\
\hline & Ambulance1 & 2 & Mobil_A2, mobil_C1 & 108,108 & Mobil_A2 \\
\hline & Ambulance1 & 2 & Mobil_A2, mobil_C1 & 108,108 & Mobil_A2 \\
\hline & Ambulance1 & 2 & Mobil_A2, mobil_C1 & 107,107 & Mobil_A2 \\
\hline & Ambulance1 & 2 & Mobil_A2, mobil_C1 & 108,108 & Mobil_A2 \\
\hline & Ambulance1 & 2 & Mobil_A2, mobil_C1 & 102,102 & Mobil_A2 \\
\hline \multirow[t]{2}{*}{9} & Mobil_A1 & 3 & $\begin{array}{c}\text { Mobil_D1, Mobil_C2, } \\
\text { Mobil_A1 }\end{array}$ & $\begin{array}{c}102,78 \\
12\end{array}$ & Mobil_D1 \\
\hline & Mobil_A1 & 2 & Mobil_D1, Mobil_C2 & 92,88 & Mobil_D1 \\
\hline 10 & - & - & - & - & - \\
\hline 11 & - & - & - & - & - \\
\hline \multirow[t]{2}{*}{12} & Ambulance2 & 2 & Mobil_D1, Mobil_A2 & 7,97 & Mobil_A2 \\
\hline & Mobil_A1 & 2 & Mobil_C2, Mobil_B2 & 88,47 & Mobil_C2 \\
\hline \multirow[t]{2}{*}{13} & Ambulance2 & 2 & Mobil_A2, Mobil_A1 & 52,72 & Mobil_A1 \\
\hline & Mobil_A1 & 2 & Mobil_A2, Mobil_C1 & 18,87 & Mobil_C1 \\
\hline 14 & Mobil_A2 & 2 & Mobil_D1, Mobil_C2 & 63,47 & Mobil_D1 \\
\hline 15 & - & - & - & - & - \\
\hline
\end{tabular}




\subsection{Pengujian Sistem terhadap Pemilihan Kendaraan Terjauh}

Pada bagian ini dilakukan pengujian dengan melakukan percobaan yang dilakukan sebanyak 15 kali dengan setiap percobaan dalam kurun waktu 10000 ms dan didapatkan 11 percobaan ditemukan pengiriman terjauh dan 4 percobaan tidak terjadi pengiriman terjauh. Dari 11 percobaan yang terjadi, kondisi penigiriman kendaraan dengan jarak terjauh dari kendaraan pengirim, paling banyak terjadi pada percobaan ke-8 dengan 13 kali kejadian. Data hasil uji terlihat pada Tabel 4 dan Tabel 5.

Tabel 5. Kejadian Pemilihan Kendaraan dengan Jarak Terjauh

\begin{tabular}{|c|c|c|}
\hline Percobaan & Range Waktu (ms) & Jumlah Kejadian (kali) \\
\hline 1 & & 1 \\
\hline 2 & & 1 \\
\hline 3 & & 1 \\
\hline 4 & & 1 \\
\hline 5 & & 1 \\
\hline 6 & & 0 \\
\hline 7 & & 1 \\
\hline 8 & 10000 & 13 \\
\hline 9 & & 2 \\
\hline 10 & & 0 \\
\hline 11 & & 0 \\
\hline 12 & & 2 \\
\hline 13 & & 2 \\
\hline 14 & & 1 \\
\hline 15 & & 0 \\
\hline
\end{tabular}

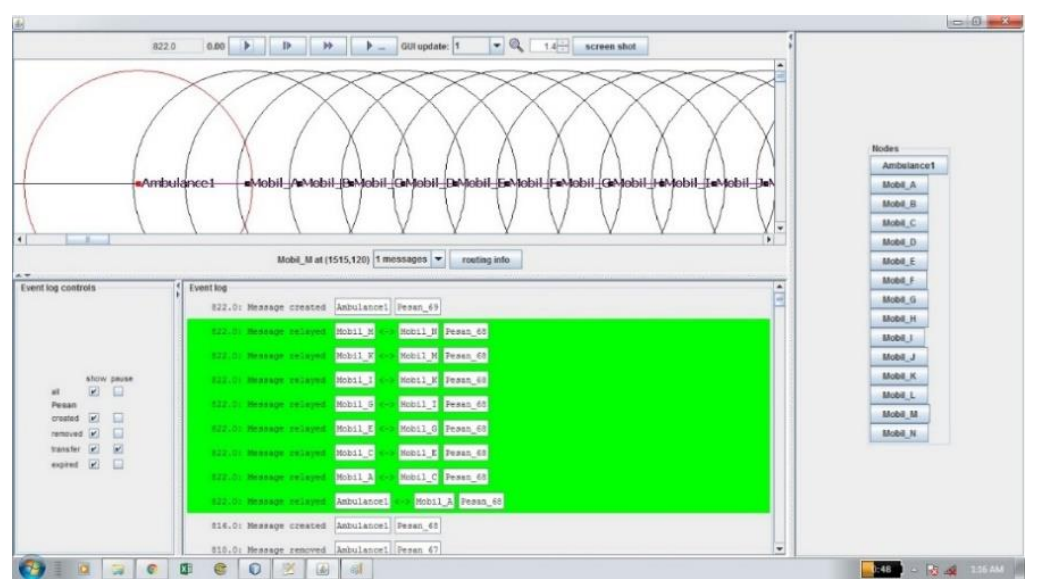

Gambar 6. Hasil Pengiriman Pesan menggunakan Protokol e-Epidemic dengan Arah Pergerakan Kendaraan Searah

\subsection{Pengujian Sistem terhadap Arah Pergerakan Kendaraan}

Dalam pengujian ini dilakukan penerapan dari arah pergerakan kendaraan baik kendaraan pengirim dan penerima. Hal ini ditujukan untuk dapat mengetahui pengaruh dari pengiriman pesan terhadap kondisi arah pergerakan kendaraan. Dalam pengujian ini, diberikan ketentuan pengiriman pesan yang dapat dilakukan berdasarkan arah pergerakan kendaraan pengirim dan penerima, yaitu "pengiriman pesan hanya dapat dilakukan jika kendaraan pengirim dan penerima memiliki arah pergerakan yang sama atau searah dan lokasi kendaraan penerima berada di depan kendaraan pengirim". Hasil uji coba terlihat pada Gambar 6 dan Gambar 7.

\subsection{Pengujian Sistem terhadap Nilai Delay}

Pengujian dilakukan untuk mengetahui pengaruh penggunaan protokol e-Epidemic terhadap Delay pengiriman pesan. Menggunakan beberapa variasi dari jumlah kendaraan, dimana dengan variasi jumlah kendaraan maka dapat diketahui waktu yang diperlukan untuk dapat mengirimkan pesan sampai pada kendaraan tujuan. Variasi dari jumlah kendaraan yang 
digunakan adalah 10 kendaraan, 20 kendaraan, 30 kendaraan, 40 kendaraan, dan 50 kendaraan. Data hasil uji terlihat pada Tabel 6 dan Tabel 7 serta grafik pada Gambar 8.

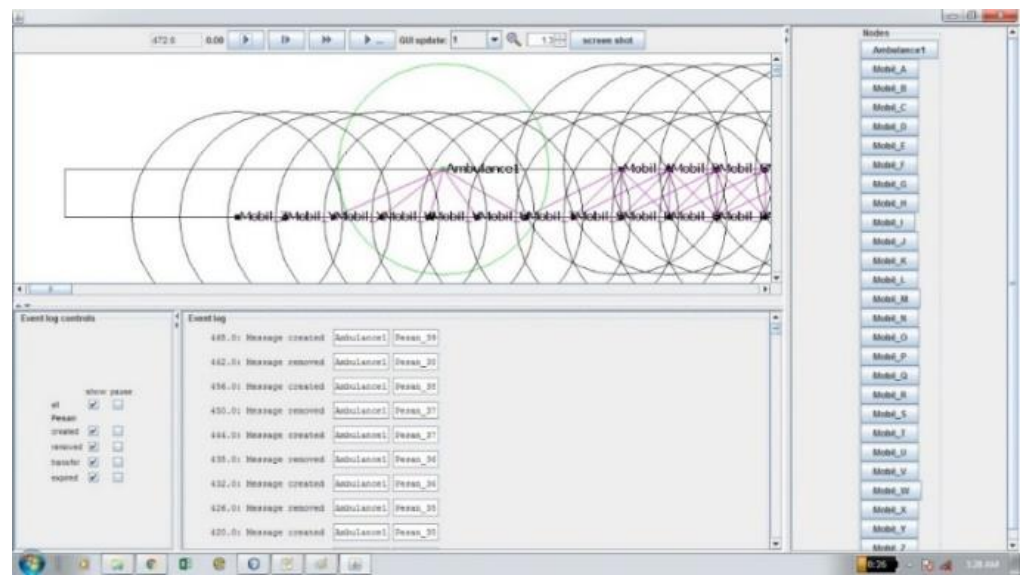

Gambar 7. Hasil pengiriman Pesan menggunakan Protokol e-Epidemic dengan Arah Pergerakan Kendaraan Dua Arah

Tabel 6. Hasil Pengujian terhadap Nilai Delay pada Protokol Epidemic dan e-Epidemic

\begin{tabular}{|c|c|c|c|c|c|c|c|c|c|c|}
\hline Protokol & $\begin{array}{c}\text { Jumlah } \\
\text { kendaraan }\end{array}$ & $\begin{array}{c}\text { Jumlah } \\
\text { Pesan }\end{array}$ & $\begin{array}{c}\text { Kendaraan } \\
\text { Awal }\end{array}$ & $\begin{array}{c}\text { Kendaraan } \\
\text { Tujuan }\end{array}$ & t1 (ms) & t2 (ms) & t3 (ms) & $\begin{array}{c}\text { Delay1 } \\
\text { (ms) }\end{array}$ & $\begin{array}{c}\text { Delay2 } \\
\text { (ms) }\end{array}$ & $\begin{array}{l}\text { Delay } \\
\text { Total } \\
\text { (ms) }\end{array}$ \\
\hline \multirow{5}{*}{$\begin{array}{c}\mathrm{e}- \\
\text { Epidemic }\end{array}$} & 10 & 34 & Mobil4 & MobilJ & $1.463 \mathrm{E}+12$ & $1.463 \mathrm{E}+12$ & $1.463 \mathrm{E}+12$ & 11591 & 499 & 12090 \\
\hline & 20 & 34 & Mobil4 & MobilJ1 & $1.463 \mathrm{E}+12$ & $1.463 \mathrm{E}+12$ & $1.463 \mathrm{E}+12$ & 11638 & 967 & 12605 \\
\hline & 30 & 34 & Mobil4 & MobilJ2 & $1.463 \mathrm{E}+12$ & $1.463 \mathrm{E}+12$ & $1.463 \mathrm{E}+12$ & 11653 & 1435 & 13088 \\
\hline & 40 & 34 & Mobil4 & MobilJ3 & $1.463 \mathrm{E}+12$ & $1.463 \mathrm{E}+12$ & $1.463 \mathrm{E}+12$ & 11700 & 1982 & 13682 \\
\hline & 50 & 34 & Mobil4 & MobilJ4 & $1.463 \mathrm{E}+12$ & $1.463 \mathrm{E}+12$ & $1.463 \mathrm{E}+12$ & 11700 & 2621 & 14321 \\
\hline \multirow{5}{*}{ Epidemic } & 10 & 241 & Mobil4 & MobilJ & $1.463 \mathrm{E}+12$ & $1.463 \mathrm{E}+12$ & $1.463 \mathrm{E}+12$ & 14025 & 16130 & 30155 \\
\hline & 20 & 241 & Mobil4 & MobilJ1 & $1.463 \mathrm{E}+12$ & $1.463 \mathrm{E}+12$ & $1.463 \mathrm{E}+12$ & 13978 & 33197 & 47175 \\
\hline & 30 & 241 & Mobil4 & MobilJ2 & $1.463 \mathrm{E}+12$ & $1.463 \mathrm{E}+12$ & $1.463 \mathrm{E}+12$ & 13869 & 49920 & 63789 \\
\hline & 40 & 241 & Mobil4 & MobilJ3 & $1.463 \mathrm{E}+12$ & $1.463 \mathrm{E}+12$ & $1.463 \mathrm{E}+12$ & 14040 & 68203 & 82243 \\
\hline & 50 & 241 & Mobil4 & MobilJ4 & $1.463 \mathrm{E}+12$ & $1.463 \mathrm{E}+12$ & $1.463 \mathrm{E}+12$ & 14040 & 86065 & 100105 \\
\hline
\end{tabular}

Tabel 7. Nilai Delay Total pada Protokol Epidemic dan e-Epidemic Berdasarkan Variasi Jumlah Kendaraan

\begin{tabular}{lccccc}
\hline \multirow{2}{*}{ Protokol } & \multicolumn{5}{c}{ Jumlah Kendaraan } \\
\cline { 2 - 6 } & 10 & 20 & 30 & 40 & 50 \\
\hline Epidemic & 30155 & 47175 & 63789 & 82243 & 100105 \\
\hline e-Epidemic & 12090 & 12605 & 13088 & 13682 & 14321 \\
\hline
\end{tabular}

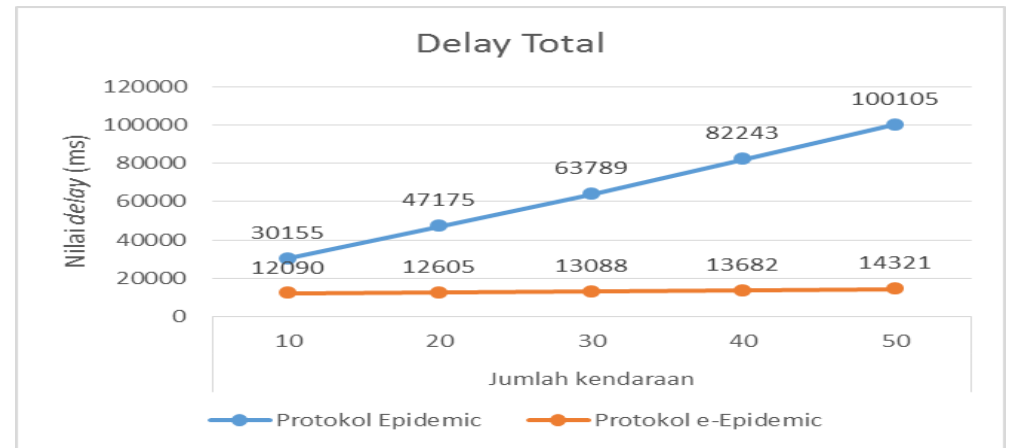

Gambar 8. Grafik Nilai Delay Total pada Protokol Epidemic dan e-Epidemic Berdasarkan Variasi Jumlah Kendaraan

\section{Kesimpulan}

Kesimpulan yang dapat diambil dari penelitian "Efisien Epidemic: Pemilihan jarak terjauh dan arah pergerakan kendaraan untuk pendistribusian pesan darurat pada VDTN" antara lain: 
1. Dihasilkan sebuah protokol usulan dari peneliti yang dinamakan dengan protokol eEpidemic. Protokol e-Epidemic merupakan pengembangan dari protokol Epidemic yang dikhususkan pada perbaikan kinerja proses pendistribusian pesan. Proses pendistribusian pesan pada protokol e-Epidemic dilakukan dengan menambahkan pengecekan arah pergerakan kendaraan, pemilihan kendaraan dengan jarak terjauh dari pengirim.

2. Penerapan protokol e-Epidemic dengan pemilihan kendaraan dengan jarak terjauh dalam radius kendaraan pengirim dan penggunaan arah pergerakan kendaraan dapat mengurangi jumlah pesan aktif yang terdapat dalam jaringan. Jumlah pesan aktif yang dimiliki ketika menggunakan protokol Epidemic adalah $92 \%$ sedangkan pada protokol e-Epidemic sebesar $8 \%$.

3. Nilai Delay yang dihasilkan pada proses pengiriman pesan dengan menggunakan Protokol Epidemic sebesar 83\%, sedangkan dengan menggunakan Protokol e-Epidemic sebesar $17 \%$.

\section{Referensi}

[1] LI, Fan; WANG, Yu. "Routing in vehicular ad hoc networks: A survey." IEEE Vehicular technology magazine, 2007, 2.2: 12-22.

[2] LAI, Peiyuan, et al. "A reliable broadcast routing scheme based on mobility prediction for VANET." In: Intelligent Vehicles Symposium, 2009 IEEE. IEEE, 2009. p. 1083-1087.

[3] DE JESUS, Vasco Nuno da Gama, et al. "Improvement of messages delivery time on vehicular delay-tolerant networks." In: 2009 International Conference on Parallel Processing Workshops. IEEE, 2009. p. 344-349.

[4] LI, Fan; WANG, Yu. Routing in vehicular ad hoc networks: A survey. IEEE Vehicular technology magazine, 2007, 2.2: 12-22.

[5] VIDHALE, Bhushan; DORLE, Sanjay S. "Performance analysis of routing protocols in realistic environment for vehicular Ad Hoc networks." In: Systems Engineering (ICSEng), 201121 st International Conference on. IEEE, 2011. p. 267-272.

[6] JONSON, Thomas, et al. "Application of delay tolerant networking (DTN) in airborne networks." In: MILCOM 2008-2008 IEEE Military Communications Conference. IEEE, 2008. p. 1-7.

[7] LU, Ziyi; FAN, Jianhua. "Delay/disruption tolerant network and its application in military communications." In: Computer design and applications (ICCDA), 2010 international conference on. IEEE, 2010. p. V5-231-V5-234.

[8] NEKOVEE, Maziar. "Epidemic algorithms for reliable and efficient information dissemination in vehicular ad hoc networks." IET Intelligent Transport Systems, 2009, 3.2: 104.

[9] RAMANATHAN, Ram, et al. "Prioritized epidemic routing for opportunistic networks." In: Proceedings of the 1st international MobiSys workshop on Mobile opportunistic networking. ACM, 2007. p. 62-66.

[10] HÄRRI, Jérôme; BONNET, Christian; FILALI, Fethi. "Kinetic mobility management applied to vehicular ad hoc network protocols." Computer Communications, 2008, 31.12: 29072924.

[11] Warthman, F. (2003). "Delay-Tolerant Networks (DTNs)": A Tutorial v1. 1. Warthman Associates.

[12] KERÄNEN, Ari; KÄRKKÄINEN, Teemu; OTT, Jörg. "Simulating Mobility and DTNs with the ONE." Journal of Communications, 2010, 5.2: 92-105. 